\title{
Are Business Management Games a Suitable Tool for Analyzing the Boundedly Rational Behavior of Economic Agents?
}

\author{
Oliver Musshoff $^{1}$, Norbert Hirschauer ${ }^{2}$, Philipp Hengel ${ }^{1}$ \\ ${ }^{1}$ Department for Agricultural Economics and Rural Development, Universität Göttingen, Göttingen, Germany \\ ${ }^{2}$ Institute of Agricultural and Nutritional Sciences, Universität Halle-Wittenberg, Halle (Saale), Germany \\ E-mail: oliver.musshoff@agr.uni-goettingen.de
}

Received June 13, 2011; revised July 14, 2011; accepted July 25, 2011

\begin{abstract}
Regulatory policies often aim to steer the behavior of economic agents by changing their economic environment. Assessing the potential impacts of regulatory policies requires forecasts regarding how humans adapt to such changes. One important prerequisite for meaningful policy impact analysis is in-depth knowledge of why and to what extent economic agents behave in a boundedly rational way. We propose that business management games can be used to contribute towards better understanding of agent behaviors, since they provide an inexpensive opportunity to reach beyond existing anecdotal evidence concerning "behavioral anomalies”. Modifying an existing business management game in which investment, financing and production decisions have to be made, we demonstrate how bounded rationality can be quantified and separated into its two components: incomplete information and limited cognitive abilities. The resulting data show that decisions made by participants in this game are strongly influenced by bounded rationality. They also show that both incomplete information and limited cognitive abilities are relevant components of the bounded rationality displayed by players.
\end{abstract}

Keywords: Bounded Rationality, Business Management Games, Multi-Period Linear Programming, Policy Impact Analysis

\section{Introduction}

Business (management) games have long been used to familiarize students with the content of economic courses [1-4]. As a byproduct of students' learning, a large amount of data accrues. With careful game design, high-quality data can be obtained under controlled conditions and at low cost. Economists should therefore consider exploiting business games for both teaching and research.

Business management games are an especially promising tool to analyze decision making in general and to examine whether and to what extent economic agents make sub-optimal decisions in particular. Sub-optimal decisions can be caused by incomplete information and/ or limited information-processing abilities. They can be understood as a deviation from rational behavior in the sense of inconsistency between individual goals and decisions actually made by each individual. Simon [5] calls this bounded rationality [6-7].
A number of social and political stakeholders are interested in steering entrepreneurial behavior by changing the economic environment. When assessing the likely impacts of such policies, forecasts need to be made regarding the way economic agents adapt to such changes. In many cases political interventions are indeed linked with the obligation to carry out an ex ante and an ex post evaluation of results in term of behavioral changes and impacts in terms of political goal achievement. A prominent example is the EU Regulation on support for rural development (Council Regulation (EC) No 1698/ 2005) and the corresponding Common Monitoring and Evaluation Framework [8] which prescribe that all rural development interventions are evaluated in order to guarantee accountability and to assess the achievements of the established political objectives.

Good forecasts require good understanding of entrepreneurial decision-making [9]. As altered economic conditions only affect micro-level decisions if they are 
actually perceived and considered in the planning process, regulatory impact analysts need to take into account the real character of economic agents, including their bounded rationality. Otherwise, one runs the risk of designing measures for economic agents who do not exist in the real world.

A quick glance at regularly surveyed economic data shows that there are significant differences in corporate success. Let's look at farming in Germany as an example. During the financial year 2007/08 the return on equity of the top third of arable farms of the national German farm accountancy data network was higher by 13.7 percentage points than that of the bottom third [10]. While this may be taken as preliminary evidence that some economic agents act less rational than others, the analysis of uncontrolled field data poses the general problem that it is often very difficult or even impossible to isolate causal relationships [11]. Besides the "degree of bounded rationality" both economic and natural situations may differ between agents. Simple examples of this are locally or regionally differing prices for land of the same quality and locally or regionally occurring damages (e.g., from hailstorms, droughts). Furthermore, different agents may pursue various other goals in addition to profit maximization such as financial security, free time or social reputation. Due to these confounding elements the degree of bounded rationality cannot be quantified based on field data on corporate performance. To isolate the effect of bounded rationality from such data, the performance that could be achieved through rational behavior would have to be known for each corporation. The performance actually attained would then have to be contrasted with this reference value. Such benchmarks cannot be provided. Their derivation would require an omniscient analyst who is able to factor in all idiosyncratic specificities in an adequate way.

Methods for retrieving data to analyze decision behavior can be classified into five ideal types along a continuum of approaches: (1) collection of naturally occurring field data, (2) collection of field data from randomized control trials, (3) collection of data through surveys where interviewees are confronted with hypothetical decision situations, (4) collection of data from business management games, and (5) collection of data from laboratory experiments. The ex ante, mid-term and ex post evaluations carried out according to the above-mentioned EU Regulation on support for rural development (Council Regulation (EC) No 1698/2005) rely mainly on the collection of naturally occurring field data. These evaluations do not represent randomized control trials. The changes of the economic environment, even though they are "artificially" induced, are not systematically designed in order to generate knowledge. Instead they result from practical political programs. Furthermore, even in ex ante evaluations, surveys with hypothetical decision situations, business management games and laboratory experiments are rarely used.

The controllability of contextual conditions and therefore internal validity in the sense that observed cor- relations can be taken as causal relationships increases from field data and surveys to management games and lab experiments. In contrast, external validity in the sense that observed relationships can be taken as being valid for relevant real-life contexts decreases from one end of the continuum to the other [12,11]. In laboratories, conditions can almost completely be controlled and deliberately varied [13]. For instance, one can determine almost exactly how much time and what utilities are used by participants and what forms of social communication are permitted. While management games allow for marginally less control, the essential characteristics of a decision situation can still be purposefully designed according to the researcher's needs. Their great advantage is furthermore that they can generate, as a by-product of a pedagogical program, reliable and easily analyzable data at very low cost.

Existing work on the quantification of bounded rationality usually resorts to surveys or lab experiments (for a review [14]). Musshoff and Hirschauer [15] analyze the magnitude of anomalies in hypothetical financing decisions made by farmers via a survey. Sandri et al. [16] use a lab experiment to examine whether decision makers follow the real options approach or exhibit bounded rationality when confronted with disinvestment situations. Gigliotti and Sopher [17] use experiments and confront agents with a set of income streams, which have a clear structure of dominance towards present-value income. The experiments show, that a large percentage of agents do not choose the payment stream that would maximize their present-value income. Trip et al. [18] use information matrices generated by specialized flower producers in workshops to analyze whether these producers consistently choose cultivars that fit their personal preferences.

This paper examines the degree of bounded rationality of students in an incentive-compatible multi-period and multi-personal business management game. The game, in which investment, financing and production decisions have to be made, is about maximizing terminal wealth in a competitive environment. That is, in contrast to most lab experiments and surveys, which are restricted to very simple partial problems, we were able to model a relatively realistic decision situation. Using various normative benchmarks, we examine the relevance of incomplete information, on the one hand, and limited information-processing capacities, on the other. To our knowledge, no existing work thus far has either explored the 
degree of bounded rationality or separated out its causes in the context of business management games.

The structure of this paper is as follows: Section 2 explains the overall study design. We first illustrate the meaning of the various normative benchmarks that are used as reference in our analysis of bounded rationality. We then describe the design of the game and the formal planning models that are used to identify the normative benchmarks. The results are described and discussed in Section 3. The paper ends with conclusions (Section 4).

\section{Design of the Study}

\subsection{Identification of Normative Benchmarks}

The essential features of the business management game can be summarized as follows: (1) players make investment, financing and production decisions in consecutive periods; (2) the players' goal in the game is to maximize terminal wealth; (3) prize money is awarded to ensure that participants carefully consider their decisions; (4) individual success depends on product prices which, in turn, result from the production decisions made by all participants; and (5) benchmarks are defined for each business showing the terminal wealth that would have been possible if more rational behavior had been employed (cf. Figure 1).

Our analysis is based on the potential improvement over each player's actual terminal wealth (point A) a fictitious player could have gained if he or she had applied formal and consistent planning. We determine consecutive reference points (benchmarks B to D) indicating the various components of improvement potential.

Reference point $\mathrm{B}$ is the result of a planning modelwhere the subjective price expectations of each player are formally processed in a methodically correct way. Being player-specific, the idiosyncratic benchmark B indicates, separately for each player, the extent to which he or she acts in a way consistent with individual expectations. A gap between A and B is the result of faulty information processing and corresponds to the first component of bounded rationality.

Reference point $\mathrm{C}$ assumes formally correct decision making based upon naïve price prognosis. While all players have the same knowledge about the rules of the game as well as the available strategies and pay-off functions, future prices are not only stochastic, but uncertain in the sense that it is impossible to determine their probability distribution. This is due to the fact that the production decisions of the other players cannot be assessed. Even though one knows that prices depend on the production decisions of all players they cannot be derived through axiomatic assumptions concerning opponents' behaviors. For such derivations, the individual amount and concrete character of the players' bounded rationality would have to be known. In this context, Arthur [19] talks of agents having to form "subjective beliefs about subjective beliefs". Another way of saying this is that the determination of a game theoretic equilibrium would require that all players had a "common knowledge of their respective bounded rationality”. Since empirical time series are not available, the probability distribution of prices cannot be determined through statistical prognosis either. In this state of information, a naïve price prognosis represents the most plausible and, thus, rational price assumption that a player can come to. In brief, benchmark $\mathrm{C}$ is based on the assumption that price changes from one period to the next are zero; i.e., the last observed price is used for planning until new information becomes available [20]. In contrast to the player-specific benchmarks $\mathrm{B}$ there is only one Benchmark $\mathrm{C}$ for all players. It indicates the terminal wealth that a fictitious player could have achie ved if he had rationally processed the most rational price expectations. As points B and $\mathrm{C}$ only differ in price assumptions, the gap between the two reflects the component of bounded rationality caused by the use of inappropriate information.

The distance between points A (actual terminal wealth) and $\mathrm{C}$ (achievable terminal wealth) reflects the total degree of bounded rationality.

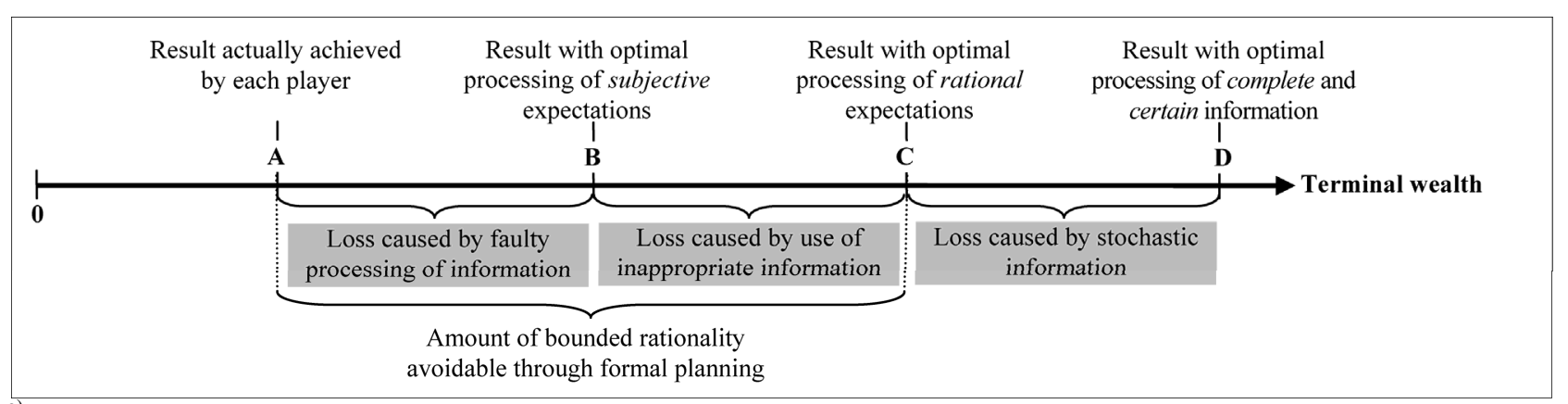

a) The exact and relative positions of points A, B and C are unknown a priori. They are rather the objects of the study.

Figure 1. Normative Benchmarks Used to Analyze Bounded Rationality. ${ }^{\text {a) }}$ 
In Figure 1, we have positioned point A to the left of benchmark B, and benchmark B to the left of benchmark C. This is not necessarily the case for all players. On the one hand, a player's price prognosis could accidentally be better than the naïve prognosis. Then, point $\mathrm{B}$ would have to be positioned to the right of point $\mathrm{C}$. On the other hand, better subjective price predictions or "lucky" combinations of inappropriate price predictions and faulty information processing could lead to even better results than correct processing of appropriate price forecasts. In such cases, players would be right for the wrong reasons. Just as a gambler has a chance of winning even the most improbable bets, a player may achieve a better result with boundedly rational behavior than through a systematic approach. If this is the case for a particular player, point $\mathrm{A}$ will lie to the right of point $\mathrm{C}$. The question whether and to what extent points A, B and C differ from each other is the subject matter of our study.

It should be noted that point $\mathrm{D}$ is the result of a model based not only on rational price expectations but unrealistically on certain information. That is, the production decisions of the other game participants are assumed to be a priori knowledge of one fictitious player. Hence, benchmark $\mathrm{D}$ can neither be beaten by actual players nor by other benchmarks. It represents an "unfair" reference since forecasts cannot be made with certainty neither in our business management game nor in reality. This is why point $\mathrm{D}$ is used only for a relative positioning of the actual results and the other benchmarks.

It should furthermore be noted that points B, C and D denote strategies which we label "individual" because they are based on the perspective that one fictitious player without influencing the game's market price ${ }^{1}$ adopts the respective strategy. A "collective" perspective (which we do not adopt) would imply that all players adopt the strategy. While coinciding with the equilibrium approach [21-22] often used in economic analysis, the collective perspective is not useful when looking for normative benchmarks in the game that is actually played. Benchmark $\mathrm{C}$, for instance, denotes the optimal strategy for a fictitious player who knows that he is playing a game with a group of boundedly rational players (cf. Table 1). Adopting the collective perspective would only yield a useful decision rule if, and only if, it were realistic to assume that the bounded rationality of all players were completely eliminated by learning (capacity building) or by competition. But then we would no longer need to explore bounded rationality.

\footnotetext{
${ }^{1}$ Even though the number of players is relatively small in our game, the production decision of one player has only a marginal effect on prices. This "price-taker-structure" is in line with the structure of many real markets where the market shares of competing players are too small to have a noticeable effect on prices.
}

Table 1. Individual vs. Collective Perspective in the Case of Benchmark C.

\begin{tabular}{lll}
\hline & Individual perspective & Collective perspective \\
\hline $\begin{array}{l}\text { Type of } \\
\text { reference } \\
\text { point }\end{array}$ & $\begin{array}{l}\text { Success of a fictitious actor } \\
\text { playing the optimal } \\
\text { strategy. }\end{array}$ & $\begin{array}{l}\text { Identical success of all } \\
\text { players playing the optimal } \\
\text { strategy. }\end{array}$ \\
Assumption & $\begin{array}{l}\text { Co-players act boundedly } \\
\text { rational. }\end{array}$ & All players act rationally. \\
\hline
\end{tabular}

\subsection{Description of the Game}

\subsubsection{Design}

We use a modified version of the business management game "Sparrow or Pigeon", which was developed for teaching purposes by Brandes [21]. The most important modification is that we offer prize money to ensure incentive compatibility. Each participant controls a business for which he or she has to decide on investments, finance and production in eight consecutive periods. Decisions have to be made weekly. Before getting started for good, players have the opportunity to play one learning round in order to get acquainted with the game.

The starting situation at the beginning of period 1 is identical for all players: everybody has a starting capital of 2,000 monetary units (MU), and everybody has the same set of entrepreneurial choices. Nobody owns any production facilities yet. Two production activities, sparrows and pigeons, can be chosen. The price for sparrows $p_{t}^{S}$ (in MU/piece) is deterministic and known to everybody:

$$
p_{t}^{S}= \begin{cases}13.5, & \text { if } t=1,2,3,4 \\ 12.0, & \text { if } t=5,6,7,8\end{cases}
$$

Due to a presumed demand shock for birds it is reduced after period $t=4$. Future pigeon prices $p_{t}^{p}$ are uncertain. They depend on aggregate pigeon production. In each period $t$, the following linear demand function applies:

$$
p_{t}^{P}=\max \left(0 ; 25-0.14 \cdot \frac{1}{N} \cdot \sum_{n=1}^{N} x_{t, n}^{P}\right)
$$

In equation (2) $N$ is the number of players participating in the game and $x_{t, n}^{P}$ the number of pigeons produced by player $n$. The size of the market is proportional to the number of players originally participating in the game. Thus, in different game cycles with different numbers of starting players, the same price is achieved if the average pigeon production per player remains the same. Stock-keeping is not possible. That is, the production of a period has to be sold at the price valid in that period.

Players can choose between five types of discrete investments to build up production capacities (cf. Table 2). Production facilities differ in terms of purchase value, 
Table 2. Overview of Investment Alternatives.

\begin{tabular}{|c|c|c|c|c|c|c|c|}
\hline \multirow{2}{*}{$\begin{array}{l}\text { Investment } \\
\text { alternative }\end{array}$} & \multirow{2}{*}{$\begin{array}{c}\text { Purchase } \\
\text { value (MU) }\end{array}$} & \multicolumn{2}{|c|}{ Production capacity ${ }^{\mathrm{a})}$} & \multirow{2}{*}{$\begin{array}{l}\text { Useful life } \\
\text { (periods) }\end{array}$} & \multicolumn{2}{|c|}{ Variable costs (MU/unit) } & \multirow{2}{*}{$\begin{array}{l}\text { Lending limit } \\
\text { (\%) }\end{array}$} \\
\hline & & Sparrows & Pigeons & & Sparrows & Pigeons & \\
\hline A & 70 & \multicolumn{2}{|c|}{20 (birds) } & 2 & 9 & 9 & 0 \\
\hline B & 195 & 25 & 0 & 3 & 8 & - & 80 \\
\hline $\mathrm{C}$ & 340 & 0 & 25 & 3 & - & 6 & 80 \\
\hline $\mathrm{D}$ & 1,560 & 75 & 0 & 3 & 3 & - & 50 \\
\hline E & 1,760 & 0 & 75 & 3 & - & 2 & 50 \\
\hline
\end{tabular}

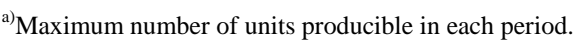

production capacity, useful life, and variable costs. Facility A uses a versatile technology that can be used for the production of sparrows or pigeons the proportion of which can be changed from one period to the next period. Facilities B, C, D, and E are specialized for the production of one or the other. Disinvestments are not possible; that is, investment costs are completely sunk. Production facilities are depreciated in a linear manner and entered in the balance sheet at their book value. The determinestic price of sparrows exceeds their production costs. Hence, there is a safe way to earn profits. Funds which are not used for production purposes yield an interest rate of $4 \%$ per period.

At the beginning of each period, players (businesses) make their investments, determine their production program and decide on how to finance their decisions. Furthermore, every business has to pay $300 \mathrm{MU}$ to the game authority to account for fixed costs. At the end of each period, the production is sold at the price according to equation (1) and (2). Furthermore, debt services are due. Subsequently, i.e., at the beginning of the next period, each player may make new decisions.

Funding requirements can be met by accumulated liquid funds (equity) or a maximum overdraft credit of $2,000 \mathrm{MU}$ at an interest rate of $15 \%$ per period. In addition, the production facilities $\mathrm{B}, \mathrm{C}, \mathrm{D}$, and $\mathrm{E}$ can be partly financed by annuity loans at an interest rate of $10 \%$ per period. The players always have to be liquid. A business is automatically retired from the game if it cannot meet its payment obligations at the beginning of a period.

The objective of the game is to accumulate the highest terminal wealth by the end of period 8 . To provide incentive compatibility, we announced the following prize money: the five players with the highest terminal wealth get $100 €\left(1^{\text {st }}\right), 80 €\left(2^{\text {nd }}\right), 60 €\left(3^{\text {rd }}\right), 40 €\left(4^{\text {th }}\right)$, or $20 €$ $\left(5^{\text {th }}\right)$. The rank of players was not disclosed until the end of the game to prevent players from dropping out because of poor performance. Besides the prize money for the top performers we also asked the players to make a price prediction at the beginning of each round for the following three periods. The best overall price prognosis was rewarded with $50 €$.

\subsubsection{Participants}

The game was played twice without changing any of the rules, once in the winter term of 2008/09 (group 1) and once in the summer term of 2009 (group 2), with participants being mostly students of agricultural science at Göttingen University. In total, 105 participants were registered (58 in group 1, and 47 in group 2). Participants who went bankrupt or did not participate during the whole game for other reasons were not included in the analysis, as benchmark B cannot be determined for these individuals. Table 3 gives an overview of the players.

We were able to analyze 23 players in each group. On average, participants in group 2 had been studying 1.2 terms longer than players in group 1 . However, they assessed their own economic abilities as being a little lower than group 1 did.

Subsequent to the game, we asked the players which utilities and decision criteria they had applied. Figure 2 gives an overview of the answers.

In this questioning more players (56) took part than we were able to include in the benchmark analysis (46), as some players who had not participated during the whole game nonetheless answered our questions.

The majority of the players used technical utilities such as spreadsheet programs (66\%) or calculators (55\%). About one fourth stated that they had made their decisions based on a "gut feeling". In addition, 45\% conducted a liquidity analysis. Furthermore, various methods of investment analysis were used for decision making. Finally, $11 \%$ stated that they had used risk analysis and linear programming models.

\subsection{Description of the Normative Benchmark Model}

\subsubsection{The Optimizing Model}

We compare the results actually achieved by the players in the game with normative benchmarks B, C and D (cf. Figure 1). These benchmarks were calculated via a mixed-integer multi-period linear programming model 
Table 3. Descriptive Statistics of Participants.

\begin{tabular}{|c|c|c|c|c|}
\hline & Number of players & $\begin{array}{c}\text { Number of analyzed } \\
\text { players }\end{array}$ & Average term of study ${ }^{\mathrm{a})}$ & $\begin{array}{c}\text { Average self-perception of } \\
\text { economic abilities }^{\text {a), b) }}\end{array}$ \\
\hline Group 1 & 58 & 23 & 4.6 & 2.70 \\
\hline Group 2 & 47 & 23 & 5.8 & 2.86 \\
\hline Total & 105 & 46 & 5.2 & 2.78 \\
\hline
\end{tabular}

${ }^{\text {a) }}$ Referring only to the analyzed players. ${ }^{\text {b) }}$ Very good $=1$ to bad $=5$.

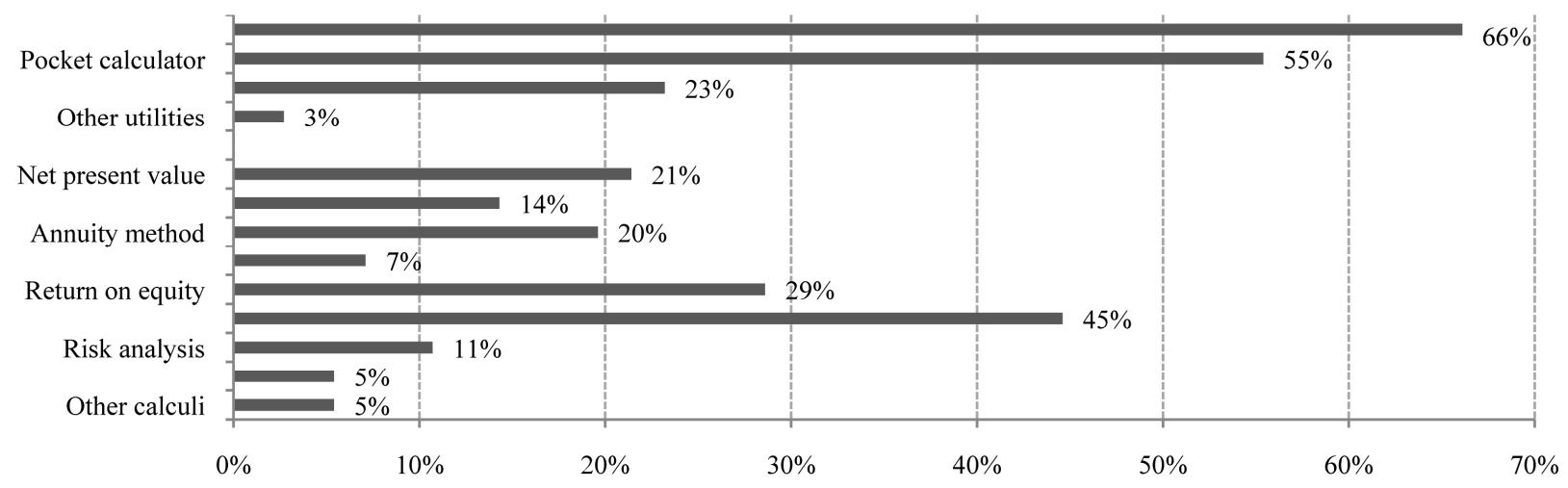

Figure 2. Utilities and Decision Criteria Used ( $\mathrm{N}=56$; multiple answers permitted).

(MLP model) which is able to consistently process information according to the rules of the game. The MLP model has the following structure:

- The model's objective function is to maximize the terminal wealth at the end of period 8 .

- In each period, the volume of investment-, production, funding and financial investment-activities can be determined. These volumes represent the model's decision variables.

- Production capacities can only be built up in whole numbers.

- There are interdependencies between investment, funding and production decisions at different points of time, as one can only produce if production capacities have been built up and financed in previous periods.

- The capital available in each period depends on accumulated liquid funds and short- and long-term loans that can be made available according to the lending limits that apply to different investments.

- The revenue surplus resulting from investment, financing and production may not fall below the fixed costs due at the beginning of each period. If this happens, a business will have to declare bankruptcy.

- As revenues are incurred at the end of a period, there is a ninth period for computation purposes. At the beginning of period 9, the book value of the production facilities is added to the deposits. Afterwards, debt capital is deduced. This gives us the terminal wealth of each player.
The structure of the MLP-model is identical for all benchmarks. Different results are caused by differing price assumptions in the benchmark models. This has the following implications:

- For identifying benchmark D, it is sufficient to solve one single eight-period MLP in period 1 as all prices that are observed after the game is finished are (unrealistically) assumed to be a priori knowledge. The resulting point $\mathrm{D}$ is a joint, but unfair, reference for all group members.

- For identifying benchmark $\mathrm{C}$, the model is initially solved in period 1 with a planning horizon of eight periods. As benchmark $\mathrm{C}$ relies on a naïve price prognosis based on the price observed in the previous period, price predictions may change from period to period. Hence, we have to solve eight sequential MLPs the planning horizons of which are sequentially reduced by one period. The resulting point $\mathrm{C}$ is a joint reference for all group members.

- For identifying benchmark B, the model is also solved in period 1 with a planning horizon of eight periods. Again, as price predictions may change over time, eight sequential models have to be solved. However, this has to be done separately for each of the 46 businesses since benchmark B is an idiosyncratic reference point based upon individual price forecasts. Consequently, 368 MLPs (8 sequential MLPs for 46 businesses) need to be solved.

- The naïve price predictions for pigeons in benchmark $\mathrm{C}$ are reduced by $1.5 \mathrm{MU}$ from period 4 to period 5 to 
account for the demand shock for birds which presumably leads both to a reduction of sparrow and pigeon prices in period 5 .

- Benchmark model B is based on subjective pigeon price forecasts that were made by the participants in each round for the following three periods. The price forecast for the third period was applied to all subsequent periods. As forecasts made in periods 1 and 2 only stretch to periods 3 and 4, pigeon prices after period 4 are analogous to benchmark model $\mathrm{C}$ reduced by $1.5 \mathrm{MU}$.

\subsubsection{Isolating Bounded Rationality}

The idea of rationality, and thus the conceptual understanding of homo œconomicus, is based on the assumption that decision makers maximize their utility. However, when defining the idea in a more specific way, it has been perceived differently. Three main interpretations can be distinguished: (1) the most narrow interpretation perceives rationality as being exercised by an optimizing homo œconomicus who maximizes profit, while costs of gathering and processing information are not taken into account. While often used for convenience, this perspective violates the assumption of utility maximization, as it abstracts not only from the costs of information gathering and processing but also from risk aversion. (2) A more realistic definition identifies rationality with an optimizing and risk-averse homo œconomicus and meta-planner. Both the utility implication of risk and the costs of information gathering and processing are accounted for. (3) A still more general definition identifies rationality simply with "consistency of decision". This perspective accords with a homo œconomicus who accounts for the cost of decision-making and consistently maximizes utility whatever his individual set of goals (income, security, social reputation, etc.) may be.

In accordance with the second concept of homo œconomicus we identify rationality with a profit-maximizing but risk-averse meta-planner who takes the costs of planning into account. From this conceptual view, two questions arise regarding the isolation of bounded rationality:

1. Can we assure that differences between players' results and benchmarks are not (partly) caused by players accounting for their individual planning costs which are unknown to the game authority?

2. Can we assure that differences between players' results and benchmarks are not (partly) caused by players exhibiting individual levels of risk aversion which are also unknown to the game authority?

Regarding question 1: Considering the impact of individual planning costs is connected to the related question of whether incentive compatibility exists to a sufficient enough degree to convince players to put serious effort into their decision-making. Due to the inevitable budgetary limitations, players could not be rewarded with the terminal wealth achieved in the game, but only with much lower prize money. This reduces the marginal revenue of additional planning efforts compared to a real-life situation where the actual realization of terminal wealth would be possible. If, for this reason, an individual player put less effort into planning, a bias due to insufficient incentive compatibility would occur. In a game, this can only be reduced but usually not completely ruled out by setting higher incentives. However, relevant literature suggests that incentive compatibility bias is marginal and may be neglected if relevant incentives are offered. If this is the case, generalizable causal relationships can be obtained from the findings of such games [23]. We argue that the offer of prize money to students in conjunction with the "will to win" observed as part of their gaming fun represent a relevant incentive and that, thus, lower performance in comparison to a benchmark can be used as a proxy for the loss caused by bounded rationality [24].

Regarding question 2: The design of the game allows for two types of outcome: First, one obtains no prize money if one is not among the top five players who achieve the highest terminal wealth. Second, one obtains prize money if one is among the top five. Due to this asymmetric payoff structure, the only relevant part of the distribution of terminal wealth is the upper $5 / \mathrm{N}$ percentile. The probability of winning (high) prize money increases if one employs strategies that lead to higher expected values and a higher volatility of terminal wealth. Higher expected values are only achievable by producing pigeons the prices of which are in contrast to sparrow prices fraught with risk. This is why regarding the "real" objective of winning prize money strategies that maximize expected terminal wealth in the game absolutely dominate other strategies. That is, the game is about maximizing expected value, independently from risk attitude. Consequently, the difference between an individual result and a benchmark represents the isolated effect of bounded rationality. In other words: the conditions have been successfully controlled to exclude a confounding risk aversion bias towards lower terminal wealth.

\section{Results}

Table 4 shows the terminal wealth achieved by the players in comparison with the normative benchmarks (cf. Figure 1). The following information is displayed:

- Column 1 (point A) shows the mean, maximum and minimum terminal wealth that was achieved by the players in the game. The average over both groups of 
Table 4. Comparison of Actual Terminal Wealth with Normative Benchmarks (in MU).

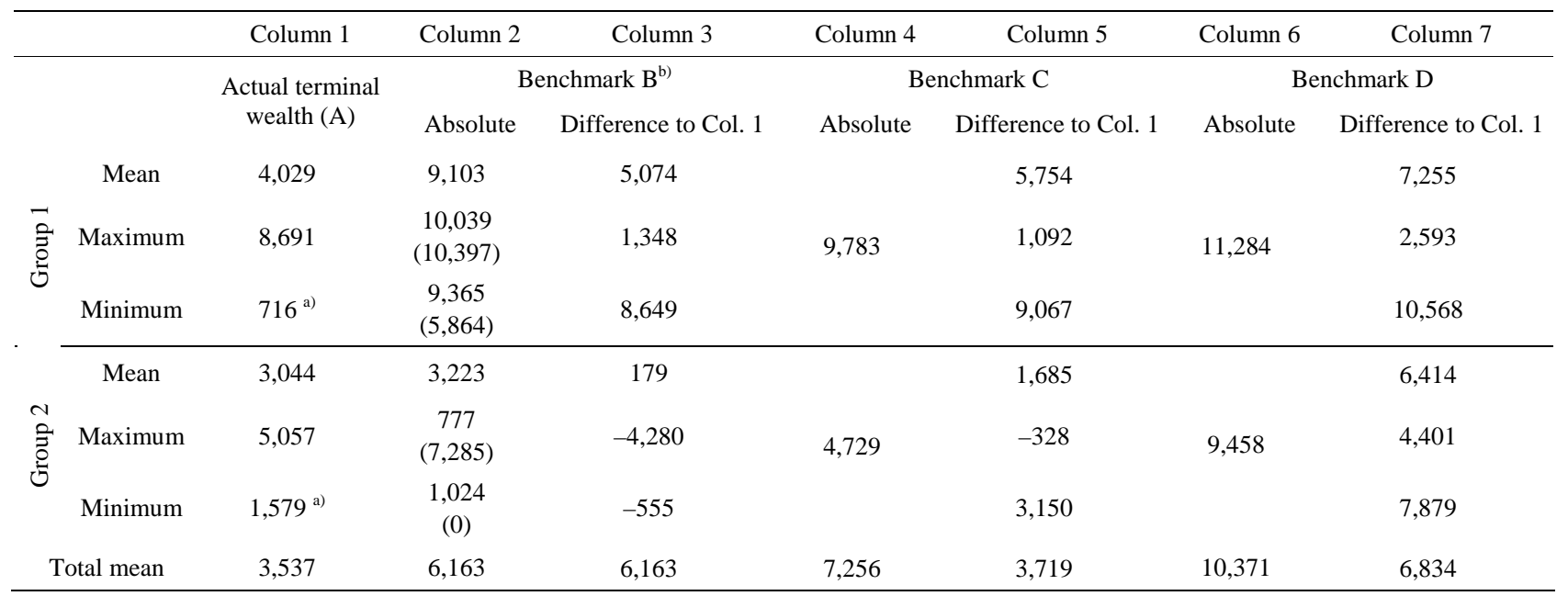

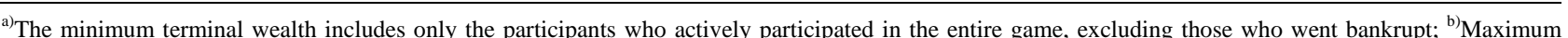
(minimum) values which are not set in brackets denote the benchmark B of the lowest (highest) performing actual business. Values in brackets, in contrast, denote the maximum and minimum of all benchmarks $B$.

players amounts to $3,537 \mathrm{MU}^{2}$

- Column 2 (point B) shows the mean, maximum and minimum terminal wealth the players could have achieved if they had correctly processed their subjective price predictions. The average over both groups amounts to 6,163 MU.

- Column 4 (point C) shows the terminal wealth a fictitious player could have gained if he had correctly processed a naïve price prognosis. It averages 7,256 MU over both groups.

Column 6 (point D) shows the terminal wealth a fictitious player could have achieved if the prices observed in the game (cf. Figure 3) had been certain a priori knowledge. This "unfair" reference point averages over both groups amounts to 10,371 MU.

Comparing the players' results with the benchmarks allows conclusions to be drawn regarding the components of bounded rationality. Figure 4 summarizes the findings.

On average, an increase of 3,719 MU could have been achieved by formal planning compared to the players' actual results. This improvement potential, which we term "amount of bounded rationality", has two components: 1,093 MU (29\%) are caused by the inappropriate formation of price expectations; and 2,626 MU (71\%) are caused by faulty information processing. A comparison of means shows that inappropriate price expectations

${ }^{2}$ Altogether, 45 businesses went bankrupt. Data from 14 other businesses could not be analyzed, because they did not actively participate in every period of the game. If one were to include the bankrupt businesses with a terminal wealth of 0 and the other 14 businesses whose terminal wealth lay between 244 and 2,631 MU in group 1 and between 49 and 2,686 MU in group 2, a mean terminal wealth of 1,682 would result. This value is about $50 \%$ lower than the terminal wealth of 3,537 MU that was achieved by the analyzed players. (t-test, $\mathrm{p}<0.01$ ) as well as faulty information processing (t-test, $\mathrm{p}<0.01$ ) are statistically significantly. Without uncertainty, that is, if the ex post observed prices had been a priori knowledge (point $\mathrm{D}$ ), the terminal wealth could have been increased by a further $3115 \mathrm{MU}$.

On average players' strategies were inferior to all benchmarks. The average terminal wealth achieved by the players (point A) is $34 \%$ of benchmark D. Since this relative performance figure is the result of an unfair comparison with a perfectly informed player, it may not seem very relevant. It is certainly remarkable, however, that actual strategies average only $49 \%$ of the achievable benchmark $\mathrm{C}$, and $57 \%$ of the idiosyncratic benchmarks B. However, not all individual strategies were inferior. For example, the best business in group 2 did better than both benchmarks B and C. And while benchmark model $\mathrm{C}$ would not have let any business go bankrupt, there is

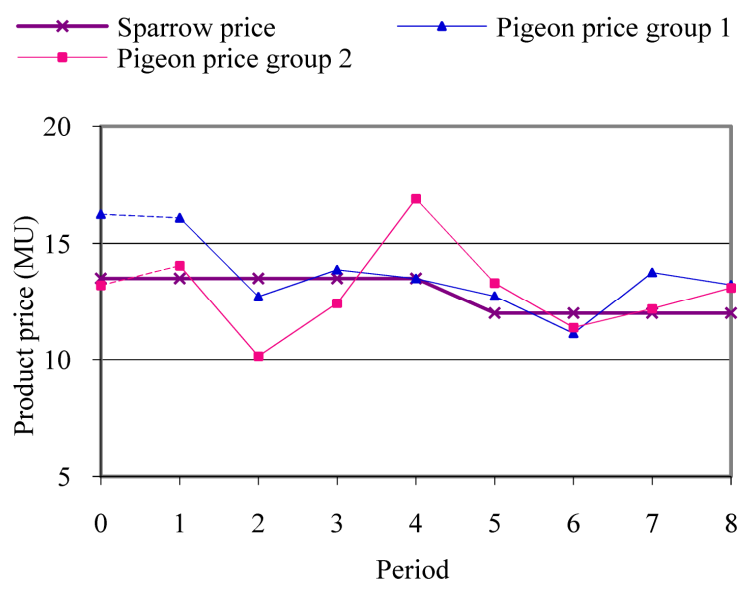

Figure 3. Price Developments of Sparrows and Pigeons. 


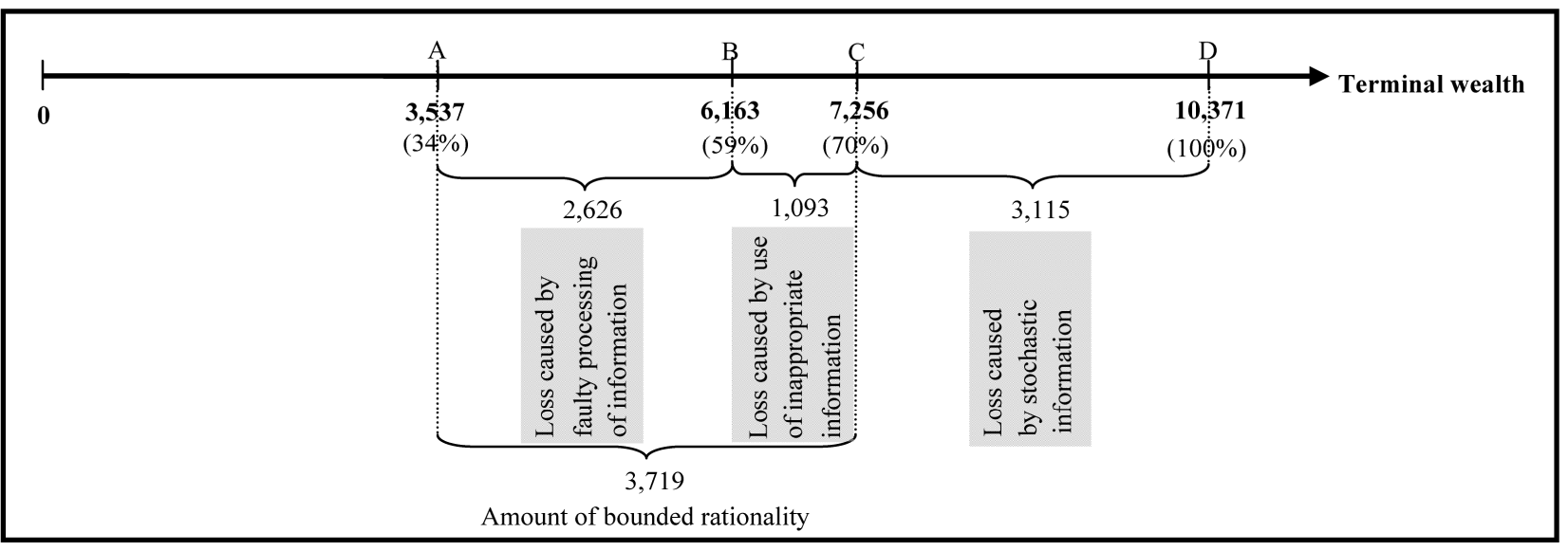

Figure 4. The Average Components of Bounded Rationality (in MU).

one case where an idiosyncratic benchmark strategy B would have ruined a business, though the individual player survived with his strategy. Absolute frequencies show a similar picture: we find that benchmark strategy $\mathrm{B}$ would have achieved better results than the players did in 31 out of 46 cases. Benchmark strategy $C$ would have achieved better results in 44 out of 46 cases.

Much discussion has been devoted to the question of whether bounded individual rationality is still observable on aggregate levels such as markets [14,25]. An alternative formulation of this question is whether markets behave in a rational way because the forces of competition guarantee that market participants adopt rational behavior. This question has gained much interest in the recent regulatory debate about the financial crisis [26]. The basic question asked in this particular debate is whether financial markets are efficient without regulation, or whether the opposite is the case. While our simple business management game is far from the complexities of financial markets, it provides a feature that may be of interest. We find that, as a result of competing players' production decisions, pigeon prices oscillate around an equilibrium price. Due to a sequence of individual overand under-reactions the market is far from equilibrium at most times. That is, the equilibrium price is only very rarely reached, and if so, only by chance. Market equilibrium in our case (and perhaps in many real markets) thus represents a "point attractor" similar to the stationary point of a clock pendulum which, if the clockwork is wound up, is only transitorily touched. The pendulum analogy implies that the understanding of market equilibrium may be necessary but not sufficient to understand and predict the decisions of boundedly rational actors and the resulting market dynamics.

\section{Conclusions}

Nearly a decade ago, Trip et al. observed that it is still in discussion whether games are suitable for research purposes [18]. While being still valid, the question today should more specifically be asked as to which games are suitable for which research purposes. This question demarcates the starting point of our study which is aimed at isolating the two components of bounded rationality: incomplete information and limited information processing abilities. For this purpose, the contextual conditions of decision-making behavior have to be clearly controlled to avoid confounding influences of uncontrolled variables. While this could be done in a lab experiment, we investigated which potential a less costly business management game has for such an analysis. We found that through careful design of the game we could con- trol the conditions sufficiently to establish internal vali- dity and answer the question of interest.

Our multi-period and multi-personal business management game relied upon a convenience sample of students of agricultural science. The performance of these student players was compared with normative benchmarks that were consistently derived from formal planning models. On average, we found that players' performance was reduced by more than $50 \%$ by bounded rationality. Over $70 \%$ of this loss, in turn, was caused by inconsistent information processing and nearly $30 \%$ by inappropriate information. These findings represent additional empirical evidence that decision makers exhibit a substantial amount of bounded rationality and that both of its components, incomplete information and limited information processing abilities, are relevant.

While producing internally valid results, the structure of our business management game is, similarly to lab experiments, devoid of many real-life complexities [27]. Furthermore, the players, being recruited from a convenience sample of students, may exhibit other characteristics than real-life actors who are of interest in a particular analysis. They may, for instance, exhibit a different 
degree or type of bounded rationality. External validity thus being low, the results have to be interpreted with caution and can only be tentatively generalized to other populations and contexts.

We can make the general conclusion that, due to the potential relevance of bounded rationality, rational-choice models are not always adequate for assessing the behavioral outcomes following changes in the economic environment. When searching for adequate models, regulatory impact analysts must therefore make a critical and deliberate choice which accounts for bounded rationality in all contexts where it exerts a significant influence on behavior.

Identifying adequate models for regulatory impact analysis is not easy, and the knowledge that decision makers may act in boundedly rational ways does not seem very helpful on first sight. This is due to the fact that constructing a decision model, that closes the gap between actual behavior and rational-choice prognoses [28], would require to reconstruct the set of choices and the calculi of individual agents. For this purpose, the heterogeneity of agents in terms of their bounded individual rationalities and assessments would need to be taken into account. Usually, this kind of individual data is either not available or prohibitively costly to come to. Thus, the attempt to define a boundedly rational choice model for each agent is out of question in most cases.

A feasible alternative may be to use context-specific business management games with representative groups of economic agents to simulate their boundedly rational adaptation to novel environments. Games with representative groups of players can be seen as an intermediate step between lab experiments and games with convenience groups, on the one hand, and field experiments in the form of randomized control trials, on the other. Such a game simulation of expected behavioral adaptation has two advantages. First, it provides an adequate combination of internal and external validity: through an apt control of conditions analysts can isolate behavioral effects caused by the policy measures under investigation. Due to the representativeness of the group, they are also able to generalize the effects identified in the game to the population of interest. Second, games with representative groups provide the opportunity to carry out an ex ante analysis of regulatory impacts. Such a prospective analysis may safe tax payers' money compared to econometric analysis and conventional randomized control trials in the field which represent an ex post evaluation after costly policy measures have been implemented.

The use of context- and group-specific business management games seems especially attractive since the costs of generating meaningful data are very low, both compared to other methods and compared to the costs of in- effective and erring policy measures. They exhibit a particular potential if the policies to be evaluated are novel, i.e., if an econometric analysis of data observed from past policy implementations and environmental conditions does not "unveil" the agents' preferences and boundedly rational behaviors under changed environments. In other words, context- and group-specific games may contribute towards less political measures being designed and implemented for agents who in reality do not exist.

Our study indicates that rational choice is not always suitable for explaining economic decision-making. Two research directions emerge from this finding: First, the behavioral economic aspects of bounded rationality need to be researched more deeply. This implies, for instance, collecting information regarding the players' socio-economic background such as education, age, income, family background, etc. It also implies investigating the decision-making process in order to disclose the algorithms, heuristics and calculi used in the decision. Second, a systematic classification of real-life situations needs to be developed, thus providing support to the political impact analyst who has to make an adequate methodical choice for the analysis of a particular policy. Such a systematization of situations could start from the distinction of two ideal-types: in highly competitive markets boundedly rational actors who are slow learners will rather quickly be "competed out of the market". In such cases, rational-choice models are rather appropriate. In contrast, in situations where competition and selection pressure are low, there will be room for prolonged boundedly rational behavior, the consequences of which can only be analyzed adequately by methods which account for the actors' true characteristics. Sometimes the distinction may not be unambiguous. In such cases, an adequate methodical choice may involve combining rational-choice models with context- and group-specific business management games.

\section{Acknowledgements}

The authors would like to thank anonymous referees and the editors for helpful comments and suggestions. We gratefully acknowledge financial support from Deutsche Forschungsgemeinschaft (DFG).

\section{References}

[1] B. Keys and J. Wolfe, "The Role of Management Games and Simulations in Education and Research," Journal of Management, Vol. 16, No. 2, 1990, pp. 307-336. doi:org/10.1177/014920639001600205

[2] J. W. Longworth, "Management Games and the Teaching of Farm Management,” Australian Journal of Agricu- 
Itural Economics, Vol. 13, No. 1, 1969, pp. 58-67.

[3] J. W. Longworth, "From War-Chess to Farm Managment Games," Canadian Journal of Agricultural Economics, Vol. 18, No. 2, 1970, pp. 1-11. doi:org/10.1111/j.1744-7976.1970.tb00897.x

[4] C. Tanner, “A Survey of Students' Attitudes to Methods of Teaching Farm Management,” Australian Journal of Agricultural Economics, Vol. 19, No. 1, 1975, pp. 52-62.

[5] H. A. Simon, "Rational Choice and the Structure of Environments,” Psychological Review, Vol. 63, No. 2, 1956, pp. 129-138. doi:org/10.1037/h0042769

[6] G. Gigerenzer and R. Selten, "Bounded Rationality: The Adaptive Toolbox,” MIT Press, Cambridge, 2002.

[7] R. Selten, “Bounded Rationality,” Journal of Institutional and Theoretical Economics, Vol. 146, No. 4, 1990, pp. 649-658.

[8] CMEF, "Common Monitoring and Evaluation Framework,” Retrieved February 18, 2011. http://ec.europa.eu/agriculture/rurdev/eval/index_en.htm.

[9] V. Smith, "Theory and Experiments: What are the Questions?” Journal of Economic Behavior and Organization, Vol. 73, No. 1, 2010, pp. 3-15. doi:org/10.1016/j.jebo.2009.02.008

[10] BMELV, "Buchführungsergebnisse der Testbetriebe 2007/2008,” 2008.

http://www.bmelv-statistik.de/de/testbetriebsnetz/buchfue hrungsergebnisse-landwirtschaft/\#c1088

[11] B. E. Roe and D. R. Just, "Internal and External Validity in Economics Research: Tradeoffs between Experiments, Field Experiments, Natural Experiments and Field Data," American Journal of Agricultural Economics, Vol. 91, No. 5, 2009, pp. 1266-1271. doi:org/10.1111/j.1467-8276.2009.01295.x

[12] K. H. Coble, Z. Yang and M. D. Hudson, "Using Experimental Economics to Evaluate Alternative Subjective Elicitation Procedures,” Applied Economics, 2009. doi:org/10.1080/0003684080.

[13] D. Hudson, "Problem Solving and Hypothesis Testing Using Economic Experiments," Journal of Agricultural and Applied Economics, Vol. 35, No. 2, 2003, pp. 337347.

[14] J. Conlisk, “Why Bounded Rationality?” Journal of Economic Literature, Vol. 34, No. 2, 1996, pp. 669-700.

[15] O. Musshoff and N. Hirschauer, "A Behavioral Economic Analysis of Bounded Rationality in Farm Financing Deci- sions: First Empirical Evidence,” Agricultural Finance Review, Vol. 71, No. 1, 2011, pp. 62-83.

[16] S. Sandri, C. Schade, O. Musshoff and M. Odening, "Holding On for Too Long? An Experimental Study on Inertia in Entrepreneurs' and Non-Entrepreneurs' Disinvestment Choices," Journal of Economic Behavior and Organization, Vol. 76, No. 1, 2010, pp. 30-44. doi:org/10.1016/j.jebo.2010.02.011

[17] G. Gigliotti and B. Sopher, "Violations of Present-Value Maximization in Income Choice," Theory and Decision, Vol. 43, No. 1, 1997, pp. 45-69. doi:org/10.1023/A:1004950613488

[18] G. Trip, R. B. M. Huirne and J. A. Renkema, "Evaluating Farmers' Choice Processes in the Laboratory: Workshops with Flower Producers,” Review of Agricultural Economics, Vol. 23, No. 1, 2001, pp. 185-201. doi:org/10.1111/1058-7195.00054

[19] W. B. Arthur, "Inductive Reasoning and Bounded Rationality," American Economic Review, Vol. 84, No. 2, 1994, pp. 406-411.

[20] H. Theil, “Applied Economic Forecasting,” Elsevier, Amsterdam, 1966.

[21] W. Brandes, "Über Selbstorganisation in Planspielen Ein Erfahrungsbericht," Schriften des Vereins für Socialpolitik, Gesellschaft für Wirtschafts-und Sozialwissen Schaften, Neue Folge Band 195/VI, 2002, pp. 61-83.

[22] A. C. Hoggatt, “An Experimental Business Game,” Behavioral Science, Vol. 4, No. 3, 1959, pp. 192-203.

[23] P. J. Schoemaker, “The Expected Utility Model: Its Variants, Purposes, Evidence and Limitations," Journal of Economic Literature, Vol. 20, No. 2, 1982, pp. 529-563.

[24] C. A. Holt, "Teaching Economics with Classroom Experiments: A Symposium”, Southern Economic Journal, Vol. 65, No. 3, 1999, pp. 603-610. doi:org/10.2307/1060819

[25] B. S. Frey and R. Eichenberger, "Anomalies in Political Economy,” Public Choice, Vol. 68, No. 1-3, 1991, pp. 71-89. doi:org/10.1007/BF00173820

[26] R. Skidelsky, "Keynes. The Return of the Master," Penguin, London, 2009.

[27] A. Tversky and D. Kahneman, "Rational Choice and the Framing of Decisions," Rational Choice, University of Chicago Press, Chicago, 1987, pp. 67-94.

[28] A. Rubinstein, "Comments on the Interpretation of Game Theory,” Econometrica, Vol. 59, No. 4, 1991, pp. 909-924. 